\title{
Prevalence, distribution, and diversity of Escherichia coli in plants manufacturing goat milk powder in Shaanxi, China
}

\author{
Meili Xi, ${ }^{1}$ Yuqing Feng, ${ }^{1}$ Qiong Li, Qinnan Yang, Baigang Zhang, Guanghui Li, Chao Shi, and Xiaodong Xia ${ }^{2}$ \\ College of Food Science and Engineering, Northwest A\&F University, Yangling, Shaanxi 712100, China
}

\begin{abstract}
The aim of the study was to investigate the prevalence, distribution, and diversity of Escherichia coli in goat-milk-powder plants in Shaanxi, China. Three plants manufacturing goat milk powder in Shaanxi province were visited once for sampling during 2012 and 2013. Samples were taken for isolation of E. coli. Isolates were characterized by antimicrobial susceptibility testing and detection of virulence genes. All isolates were further examined by pulsed-field gel electrophoresis analysis. In total, $53 \mathrm{E}$. coli strains were isolated from 32 positive samples out of 534 samples. Among $E$. coli isolates, resistance was most frequently observed to trimethoprim-sulfamethoxazole $(75.5 \%)$, whereas all isolates were sensitive to gatifloxacin, kanamycin, amikacin, and amoxicillin-clavulanate. The 6 virulence genes of pathogenic E. coli were not detected. Pulsedfield gel electrophoresis results showed that E. coli strains in plants were genetically diverse and milk storage tank could be an important contamination source. This study could provide useful information for plants manufacturing goat milk powder to establish proper management practices that help minimize the chance of microbial contamination.
\end{abstract}

Key words: Escherichia coli, goat milk powder, antimicrobial resistance, virulence gene

\section{INTRODUCTION}

Goat milk accounted for about $2.3 \%$ of the worldwide milk production (Claeys et al., 2014). Goat farming is of vital importance for the national economy in many countries in the Mediterranean and Middle East region and is particularly well organized in France, Italy, Spain, and Greece (Park et al., 2007). Among the Eu-

Received November 2, 2014.

Accepted January 4, 2015.

${ }^{1}$ These 2 authors contributed equally to this article.

${ }^{2}$ Corresponding author: foodscixiaodong@yahoo.com ropean countries, Greece has the largest goat population (6,000,000 animals) and produces about 450,000 $\mathrm{t}$ of goat milk per year (Anifantakis, 2001). Goat milk and its products have 3 significant benefits in human nutrition: (1) feeding more starving and malnourished people in the developing world than cow milk; (2) serving people afflicted with cow-milk allergies and gastrointestinal disorders, which is a significant segment in many populations of developed countries; and (3) meeting the gastronomic needs of connoisseur consumers, which has a growing market share in many developed countries.

Escherichia coli in raw milk is inactivated by pasteurization but may enter dairy powder after processing, such as during the drying process (IDF, 1991). Escherichia coli is regarded by the dairy industry as an important indicator of manufacturing hygiene, and this group, or the coliform subgroup, is widely included in microbial specifications or guidelines for dairy powders in various countries. Pathogenic E. coli in improperly pasteurized milk has caused foodborne outbreaks, and antimicrobial resistance of $E$. coli is another concern of the public. It was shown that when considering 60 outbreaks and 4 single cases described in the literature and implicating milk and milk products, pathogenic $E$. coli were responsible for 11 outbreaks (De Buyser et al., 2001). In 2009, a study revealed the presence of pathogenic $E$. coli in dairy powder factory environments (Duffy et al., 2009). A study from Ireland showed that the occurrence of the virulence gene of $E$. coli in raw milk was $36.0 \%$, whereas the occurrence of isolates was 0.8\% (Lynch et al., 2012).

Owing to the unique properties of goat milk, it has been widely consumed in some regions of the world and by a considerable portion of the population. And, goat milk-based infant formula is becoming more and more preferred by consumers. However, there is a paucity of data regarding $E$. coli contamination in goat milk and plants, except a study on the E. coli in dairy powder factory environments (Duffy et al., 2009). The objective of this study was to determine the prevalence of E. coli strains in goat milk powder in the year of 2012 and 2013 from 4 plants in Shaanxi province, China, 
and characterize these strains by antimicrobial susceptibility testing and toxin-gene detection. In addition, pulsed-field gel electrophoresis (PFGE) profiles of isolates were compared to identify the possible source of contamination at different stages and sampling sites of the processing line.

\section{MATERIALS AND METHODS}

\section{Sampling Design and Collection}

Three plants manufacturing goat milk powder in Weinan (plant A), Jingyang (plant B), and Yanliang (plant C) were selected in Shaanxi province, China. Plants were sampled once from December 2012 to March 2013, with an interval of about 1 mo between sampling of each plant. Latex gloves and disposable plastic boot covers were worn for sample collection. Gloves were disinfected with $75 \%$ ethanol before sample collection. A total of 534 various types of samples were collected, including milk powder and environmental swabs. Sites for sampling covered most procedures in the plant, and the nonprocessing and processing environments of the 3 plants were also considered. In detail, a total of 28 , 29, and 19 sites were chosen for sampling in Weinan, Jingyang, and Yanliang, respectively. At each site, at least 3 samples were collected (Table 1).

Samples were collected as follows: $100 \mathrm{~cm}^{2}$ of environmental surfaces were collected using a sterile cotton swab rehydrated with $10 \mathrm{~mL}$ of buffered peptone water; $500 \mathrm{~g}$ of goat-milk powder was collected using sterile sample bags; $500 \mathrm{~mL}$ of liquid goat milk was collected using a sterile bottle; and air samples were collected by exposing Luria-Bertani plates in the air for $5 \mathrm{~min}$. All samples were transported on ice and processed within $24 \mathrm{~h}$ of collection.

\section{Escherichia coli Enrichment and Isolation}

All samples were used for the isolation and identification of E. coli (Duffy et al., 2009). Briefly, $10 \mathrm{~mL}$ (or $10 \mathrm{~g}$ ) of samples was mixed with $90 \mathrm{~mL}$ of buffered peptone water. The solution was incubated at $37^{\circ} \mathrm{C}$ overnight. After preenrichment, a 1-mL aliquot was transferred to $10 \mathrm{~mL}$ of E. coli broth (EC; Beijing Land Bridge Technology Ltd., Beijing, China) and incubated at $44^{\circ} \mathrm{C}$ for $22 \pm 2 \mathrm{~h}$. Samples that were positive for the presence of gas were streaked onto eosin methylene blue agar (Beijing Land Bridge Technology Ltd.). Two presumptive E. coli colonies per sample were transferred to trypticase soy agar plates. Colonies were then confirmed as E. coli by PCR detection of the uidA gene. All isolates were stored at $-80^{\circ} \mathrm{C}$ until use.

\section{PCR Detection}

Six virulence genes specific for each type of diarrheagenic $E$. coli were tested by PCR method: the eae gene for enteropathogenic $E$. coli, the ipaH gene for enteroinvasive $E$. coli, the elt and est gene for enterotoxigenic $E$. coli, the $a g g R$ gene for enteroaggregative $E$. coli, and the stx gene for Shiga toxin-producing E. coli (STEC). Primers for the PCR assays are list in Table 2. The PCR products were resolved by $1.0 \%$ (wt/vol) agarose gel electrophoresis in $0.5 \times$ Tris-borate-EDTA buffer.

\section{Serotyping}

Pathogenic E. coli isolates were serotyped in the Henan Center for Disease Control and Prevention, China. $\mathrm{O}$ and $\mathrm{H}$ antigens were characterized using slide agglutination with hyperimmune sera (S\&A Company, Bangkok, Thailand), and the serotype was assigned following the manufacturer's instructions.

\section{Antimicrobial Susceptibility Testing}

Antimicrobial susceptibility testing of E. coli was performed by the agar dilution method for ciprofloxacin, nalidixic acid, gatifloxacin, ampicillin, gentamicin, kanamycin, amikacin, streptomycin, cefoxitin, cefoperazone, ceftriaxone, trimethoprim-sulfamethoxazole, amoxicillin-clavulanate, chloramphenicol, and tetracycline. Escherichia coli ATCC 25922 and Enterococcus faecalis ATCC 29212 were used as quality control strains in each run. The breakpoints used for $E$. coli were taken according to guidelines developed by the Clinical Laboratory Standard Institute (CLSI, 2013).

\section{PFGE}

Pulsed-field gel electrophoresis of XbaI (TaKaRa, Dalian, China)-digested genomic DNA of E. coli strains was carried out as described previously (Gautom, 1997). The PFGE conditions of $X b a I$ macrorestriction analysis were $6 \mathrm{~V} / \mathrm{cm}$ for $19 \mathrm{~h}$ with pulse times ranging from 2.16 to $54.17 \mathrm{~s}$ at a temperature of $14^{\circ} \mathrm{C}$ and an angle of $120^{\circ}$.

The gels were stained with ethidium bromide, and images were taken under UV transillumination (BioRad, Hercules, CA). The images were analyzed using the BioNumerics Software (Applied-Maths, Kortrijk, Belgium) by using DICE coefficients and the unweighted-pair group method to achieve dendrograms with an optimization value of $0.5 \%$ and a $1.0 \%$ band position tolerance. The cluster cutoff was set at $85 \%$ similarity. Genomic DNA of Salmonella serotype Branderup strain H9812 digested with $\mathrm{XbaI}$ was used as a molecular-size marker. 
Table 1. Sampling design for determining Escherichia coli contamination in 3 plants manufacturing goat milk powder in Shaanxi, China

\begin{tabular}{|c|c|c|c|c|}
\hline Source of sample & Plant A & Plant B & Plant C & Total \\
\hline Soil around the plants & 5 & 10 & 10 & 25 \\
\hline Shoes & $\mathrm{NT}^{1}$ & 5 & NT & 5 \\
\hline Vents of packing rooms & 5 & 5 & 5 & 15 \\
\hline Vents of fluidized beds & 5 & NT & NT & 5 \\
\hline Wall of air-filter rooms & NT & NT & 5 & 5 \\
\hline Wall of packing rooms & 5 & NT & 5 & 10 \\
\hline Wall of spray-dryer rooms & NT & 5 & 5 & 10 \\
\hline Ground of fluidized-bed rooms & 5 & NT & NT & 5 \\
\hline Ground of spray-dryer rooms & 5 & 5 & 5 & 15 \\
\hline Ground of fluidized beds & 5 & NT & NT & 5 \\
\hline Ground of packing rooms & 10 & 10 & 5 & 25 \\
\hline Ground of air filters & NT & NT & 5 & 5 \\
\hline Windows of spray-dryer rooms & NT & 5 & NT & 5 \\
\hline Windows of packing rooms & NT & 5 & NT & 5 \\
\hline Air filters & 5 & 10 & 10 & 25 \\
\hline Air of air-drying rooms & NT & 4 & NT & 4 \\
\hline Air of packaging rooms & NT & 2 & NT & 2 \\
\hline Air of spray-dryer rooms & NT & 2 & NT & 2 \\
\hline Air of air-filter rooms & NT & 4 & NT & 4 \\
\hline Water in the pipelines & NT & 5 & NT & 5 \\
\hline Water for washing & NT & NT & 5 & 5 \\
\hline Powder on the ground of packing rooms & NT & 7 & NT & 7 \\
\hline Powder around the spray dryers & NT & 13 & NT & 13 \\
\hline Powder on the ground of cooling-down machine rooms & NT & NT & 4 & 4 \\
\hline Operation desks & 4 & 20 & NT & 24 \\
\hline Packing material & 8 & NT & NT & 8 \\
\hline Outside surface of packages & NT & 6 & NT & 6 \\
\hline Inside surface of packages & NT & 4 & NT & 4 \\
\hline Products & NT & 27 & 41 & 68 \\
\hline Conveyor & 10 & 10 & 5 & 25 \\
\hline Powder sifters & 3 & NT & 5 & 8 \\
\hline Packing machines & 15 & NT & 5 & 20 \\
\hline Milk clarifiers & 2 & NT & NT & 2 \\
\hline Outside surface of milk clarifiers & 3 & NT & NT & 3 \\
\hline Outside surface of balancing tanks & 2 & NT & NT & 2 \\
\hline Inside surface of balancing tanks & 2 & NT & NT & 2 \\
\hline Inside surface of fluidized beds & 6 & NT & NT & 6 \\
\hline Outside surface of fluidized beds & 4 & NT & NT & 4 \\
\hline Inside surface of drying towers & 2 & NT & NT & 2 \\
\hline Evaporators & 3 & NT & NT & 3 \\
\hline Inside surface of tankers & 10 & NT & NT & 10 \\
\hline Inside surface of spray dryers & 13 & 5 & NT & 18 \\
\hline Spray dryers & 5 & 2 & NT & 7 \\
\hline Storage tanks & 3 & 5 & NT & 8 \\
\hline Outside surface of spray dryers & 5 & 13 & 5 & 23 \\
\hline Inside surface of powder sifters & 5 & NT & NT & 5 \\
\hline Milk storage tanks & NT & 5 & 5 & 10 \\
\hline Sealing machines & NT & 5 & NT & 5 \\
\hline Inside surface of tanks & NT & 5 & NT & 5 \\
\hline Cooling-down machines & NT & 20 & NT & 20 \\
\hline Fluidized beds & NT & NT & 5 & 5 \\
\hline Sieve beds & NT & NT & 20 & 20 \\
\hline Total & 155 & 224 & 155 & 534 \\
\hline
\end{tabular}

${ }^{1}$ Not tested.

\section{RESULTS}

\section{Isolation of E. coli}

Of the 534 samples, $32(6.0 \%)$ samples were positive for E. coli, including $24(17.0 \%)$ of the 224 samples from the plant in Jingyang and $8(9.0 \%)$ of the 155 samples from the plant in Yanliang. A total of $53 \mathrm{E}$. coli isolates were recovered from the $32 \mathrm{E}$. coli-positive samples ( 1 or 2 isolates per sample; Table 3 ).

The vast majority of $E$. coli-positive samples were obtained from the milk storage tanks (100\% positive rate samples in Jingyang; $80.0 \%$ positive rate samples in Yanliang). The final milk powder in the package was contaminated at a rate of $4.0 \%$ with $E$. coli. 


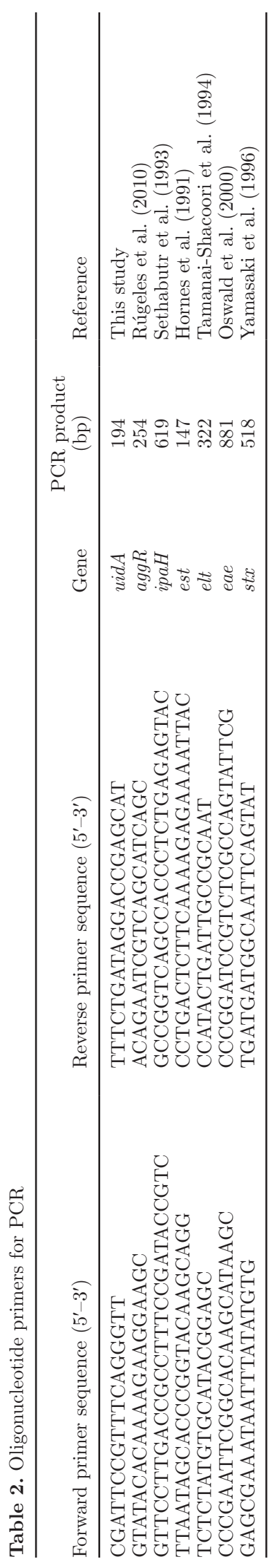

\section{Serotyping and Virulence Detection}

Serotyping results showed that not all isolates could be typed by the available $\mathrm{O}$ antigens and $\mathrm{H}$ antigens. $\mathrm{O}$ antigens of 10 isolates and $\mathrm{H}$ antigens of 17 isolates could not be determined. Many isolates (11 of 35 isolates) belonged to serotype O125:H5, whereas the other 4 typeable isolates exhibited different serotypes: O1:H2, O125:H18， O27:H5， O27:H18， O121:H5， O18:H2, O27:H2, O63:H5, O103:H40, and O115:H40 (Figure 1). Different $\mathrm{O}$ types were observed in $8 \mathrm{H}$-nontypeable isolates, among which isolates $426 \mathrm{~A}$ and $426 \mathrm{~B}, 428 \mathrm{~A}$ and $428 \mathrm{~B}, 560 \mathrm{~A}$ and $560 \mathrm{~B}$, and $679 \mathrm{~A}$ and $679 \mathrm{~B}$ reacted with the same $\mathrm{O}$ antiserums. Among 53 isolates of $E$. coli, none of the 6 virulence genes tested was detected.

\section{Antimicrobial Susceptibility Testing}

Of the $53 \mathrm{E}$. coli isolates, resistance was most frequently observed to trimethoprim-sulfamethoxazole (75.5\%), followed by streptomycin (32.7\%), and to a lesser extent ampicillin (20.8\%), tetracycline (20.8\%), nalidixic acid (7.6\%), cefoxitin $(7.6 \%)$, chloramphenicol $(7.6 \%)$, cefoperazone $(5.7 \%)$, gentamicin $(5.7 \%)$, ciprofloxacin $(3.8 \%)$, and ceftriaxone $(3.8 \%)$. All $E$. coli isolates were susceptible to amikacin, gatifloxacin, kanamycin, and amoxicillin-clavulanic acid. Forty-three E. coli isolates $(81.1 \%)$ were resistant to at least 1 antibiotic, and $13 \mathrm{E}$. coli isolates $(24.5 \%)$ were resistant to at least 3 antibiotics (Table 4 ).

\section{PFGE}

All of $53 \mathrm{E}$. coli isolates were analyzed for genetic relatedness using PFGE with $X b a \mathrm{I}$. Using a cutoff value of 85\%, 20 different PFGE patterns were generated, including 13 clusters and 7 individual types (Figure 1). The 3 most predominant PFGE clusters were observed in $14(26.4 \% ; 14 / 53)$ isolates grouped in cluster $\mathrm{J}, 5$ $(9.4 \% ; 5 / 53)$ isolates in cluster E, $4(7.5 \% ; 4 / 53)$ isolates in cluster $\mathrm{C}$, and $4(7.5 \%$; $4 / 53)$ isolates in cluster M.

\section{DISCUSSION}

This study was carried out to assess E. coli contamination in goat-milk-powder plants in Shaanxi province, which is the largest goat-milk production area in China. Intervention based on the findings should help to reduce or eliminate microbial contamination from plants processing goat milk powder.

In the present study, isolates of $E$. coli came from 3 plants, and E. coli was not detected in the plant of Weinan. The overall contamination rate of E. coli in the 
Table 3. Percentage occurrence of Escherichia coli in the environments of 3 milk-powder plants

\begin{tabular}{lccc}
\hline & \multicolumn{2}{c}{ \% Samples (positive/number tested) } \\
\cline { 2 - 4 } Environment & Plant B & Plant C & Total \\
\hline Milk storage tanks & $100.0(5 / 5)$ & $80.0(4 / 5)$ & $90.0(9 / 10)$ \\
Vents of packing rooms & $60.0(3 / 5)$ & ND $^{1}$ & $60.0(3 / 5)$ \\
Soil around the plant & ND & $40.0(4 / 10)$ & $40.0(4 / 10)$ \\
Water in the pipelines & $40.0(2 / 5)$ & $\mathrm{ND}$ & $40.0(2 / 5)$ \\
Powder on the ground of packing rooms & $28.6(2 / 7)$ & $\mathrm{ND}$ & $28.6(2 / 7)$ \\
Operation desks & $20.0(4 / 20)$ & $\mathrm{ND}$ & $20.0(4 / 20)$ \\
Air filters & $20.0(2 / 10)$ & $\mathrm{ND}$ & $20.0(2 / 10)$ \\
Conveyor & $10.0(1 / 10)$ & $\mathrm{ND}$ & $10.0(1 / 10)$ \\
Ground of packing rooms & $10.0(1 / 10)$ & $\mathrm{ND}$ & $10.0(1 / 10)$ \\
Outside surface of spray dryers & $7.7(1 / 13)$ & $\mathrm{ND}$ & $7.7(1 / 13)$ \\
Powder around the spray dryers & $7.7(1 / 13)$ & $\mathrm{ND}$ & $7.7(1 / 13)$ \\
Cooling-down machines & $5.0(1 / 20)$ & $\mathrm{ND}$ & $5.0(1 / 20)$ \\
Products & $3.7(1 / 27)$ & $\mathrm{ND}$ & $3.7(1 / 27)$ \\
Total & $16.6(24 / 145)$ & $53.3(8 / 15)$ & $20.0(32 / 160)$ \\
\hline
\end{tabular}

${ }^{1}$ Not detected.

samples was $6.0 \%(32 / 534)$, which is much lower than that reported in the Australian dairy powder factory environments (Duffy et al., 2009). The difference in sampling design may account for the discrepancy. The study in Australian dairy powder factory environments focused on the surfaces of drains, gutters, and shoes.

Escherichia coli was isolated at a high frequency from milk storage tanks $(90.0 \%, 9 / 10)$, which highlights the need for vigilance of preventing cross-contamination into spray-drying facilities. The packing-room environment was identified as an important contamination source. Operation desks, vents, ground, end products, and powder on the ground in the packing room were found to be contaminated.

In recent years, the emergence of multiple-antimicrobial-resistant strains of $E$. coli, particularly multidrugresistant strains leading to either community-acquired and nosocomial infections, has become a major publichealth concern (Xu et al., 2014). Many researchers have reported resistant $E$. coli isolated from various food samples in different countries (Yang et al., 2004; Mora et al., 2005; Ho et al., 2011), but antimicrobial resistance of $E$. coli in plants manufacturing goat milk powder has rarely been reported. In the current study, only $10(18.9 \%) E$. coli isolates were sensitive to all tested antibiotics, whereas $24.5 \%$ (13/53) of E. coli isolates showed multidrug resistance (resistant to at least 3 antimicrobials). Resistance to trimethoprim-sulfamethoxazole is common (75.5\%) among E. coli isolates. Compared with antimicrobial-resistance rates of E. coli isolates from other food samples (Koo and Woo, 2011; Vieira et al., 2011), resistance to these antimicrobials in isolates from milk powder plants is generally lower. In Korea, a previous study showed that $67.8 \%$ of $E$. coli isolated from meat and meat products were resistant to streptomycin, $66.1 \%$ to ampicillin, $44.6 \%$ to cipro- floxacin, $41.3 \%$ to trimethoprim-sulfamethoxazole, and $26.4 \%$ to chloramphenicol. The antimicrobial resistance of isolates from goat-milk plants is different from that from other meats and meat products. This may be explained by the fact that generally, less antibiotics were used in goat farms than in pig or cow farms in China.

The 53 isolates were not found to carry any of the 6 virulence genes of $E$. coli, which may be due to the limited number of isolates tested. Duffy et al. (2009) showed that only 3 (1\%) of all environmental E. coli isolates carried the virulence genes esc $V$ and eaeA. Several studies (Beutin et al., 1993; Blanco et al., 2003; Rey et al., 2003; Jacob et al., 2013) have shown that goat could be the reservoir of STEC. However, we did not find existence of STEC in the plants manufacturing goat milk powder. In the plants we selected, most frequent serotypes of $E$. coli isolates were O125:H5 and $\mathrm{O} 1: \mathrm{H} 2$, which differed from the serotypes of $E$. coli isolates reported in previous studies focusing on STEC (Cortés et al., 2010; Martin and Beutin, 2011; Scheutz et al., 2011).

The molecular typing of isolates by PFGE revealed the presence of multiple clones of $E$. coli within each plant. With one exception, these strains from different plants were grouped in different clusters. Only cluster $\mathrm{J}$ contained isolates from 2 plants with more than $85 \%$ similarity. As shown in Figure 1, PFGE grouped isolates from different samples and from different locations, indicating a certain degree of spread of specific clones in the dairy environment. Milk in different storage tanks was contaminated by $E$. coli of various PFGE patterns (such as strain $427,429,430$ ), indicating that the possible contamination source is the storage tank, because milk samples were of the same lot when loaded into tanks. Cluster J included E. coli with an identical PFGE pattern isolated from a conveyor, powder around 
Dice (Opt0.50\%) (Tol 1.0\%-1.0\%) (H>0.0\% S $\% 0.0 \%)[0.0 \%-100.0 \%]$

Escherichia col Escherichia col

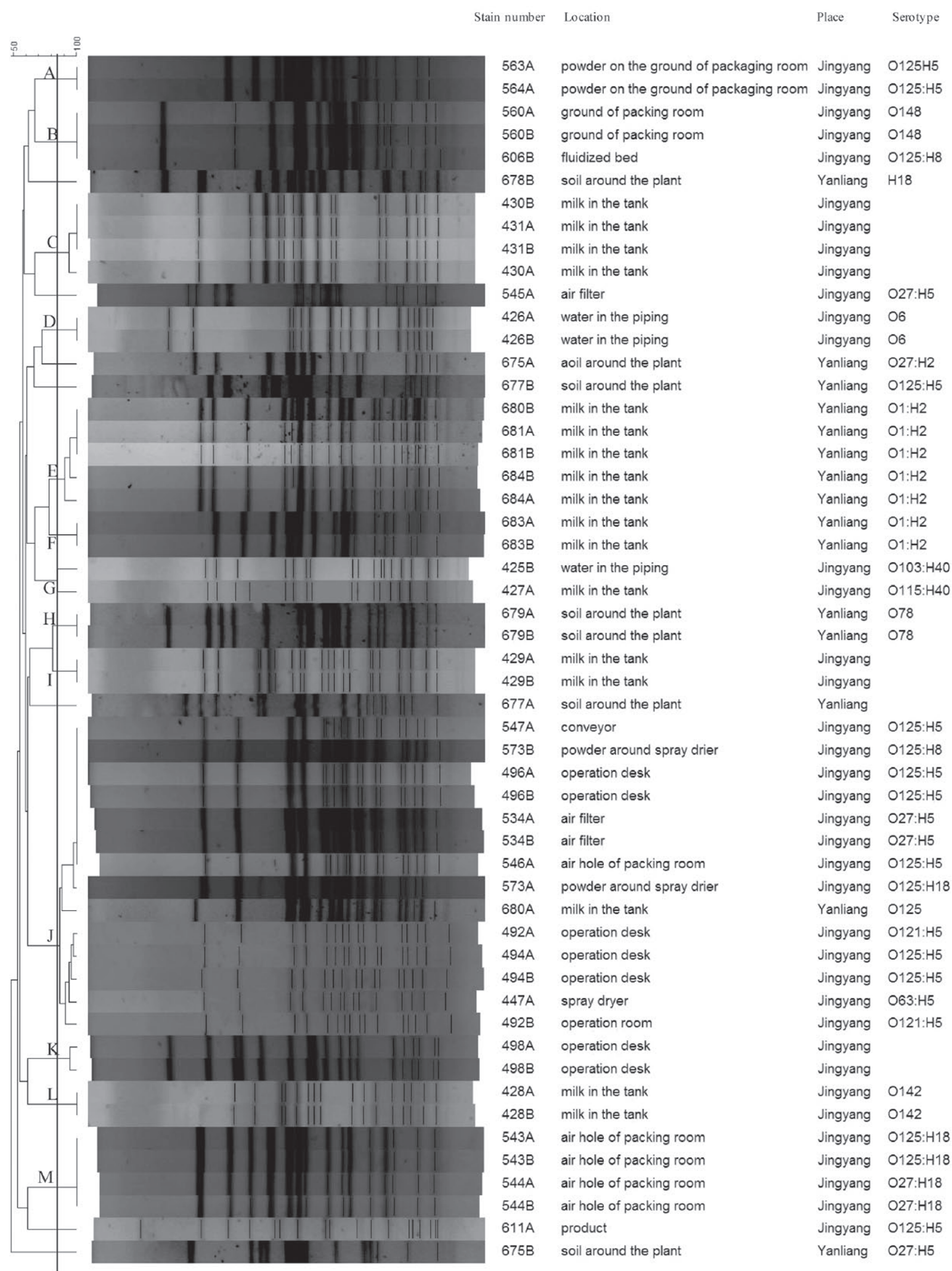

Figure 1. Dendrogram of pulsed-field gel electrophoresis patterns showing the relatedness of Escherichia coli isolated from milk powder plants. The cluster cutoff was set at $85 \%$ similarity. 
Table 4. Multidrug resistance among Escherichia coli isolates recovered from the plants

\begin{tabular}{lccc}
\hline & \multicolumn{3}{c}{ Source [No. (\%) of isolates] } \\
\cline { 2 - 4 } $\begin{array}{l}\text { No. of antimicrobials } \\
\text { to which resistance was shown }\end{array}$ & $\begin{array}{c}\text { Plant in Jingyang } \\
(\mathrm{n}=38)\end{array}$ & $\begin{array}{c}\text { Plant in Yanliang } \\
(\mathrm{n}=15)\end{array}$ & $\begin{array}{c}\text { Total } \\
(\mathrm{n}=53)\end{array}$ \\
\hline 0 & $6(15.8)$ & $4(1.6)$ & $10(18.9)$ \\
1 & $17(44.7)$ & $7(46.7)$ & $24(45.3)$ \\
2 & $5(13.2)$ & $1(6.7)$ & $6(11.3)$ \\
3 & $1(2.6)$ & $2(13.3)$ & $3(5.7)$ \\
4 & $3(7.9)$ & $1(6.7)$ & $4(7.5)$ \\
5 & $2(5.3)$ & $0(0.0)$ & $2(3.8)$ \\
6 & $2(5.3)$ & $0(0.0)$ & $2(3.8)$ \\
$>6$ & $2(5.3)$ & & $2(3.8)$ \\
\hline
\end{tabular}

spray drier, operation desk, and air filter and air hole of packing room, suggesting dissemination of one clone in the packing area. We speculate that E. coli may be transmitted by air, which has also been reported in an early study (Craven et al., 2010). This highlights the importance of maintaining good hygiene at this stage of packaging.

In summary, this study demonstrated the presence of E. coli in plants manufacturing goat milk powder in Shaanxi Province, China. Milk storage tank and air in the plant could be potential sources of contamination. These findings provide useful information for the milk-powder industry to establish proper management practices that help minimize the chance of microbial contamination.

\section{ACKNOWLEDGMENTS}

This work was supported in part by the TwelveFive Science and Technology Support Program (No. 2012BAH30F03), the Science and Technology Development Plan Program of Shaanxi Province (2013KJXX16), the Program for New Century Excellent Talent Support Plan (NCET-13-0448), and the International Science and Technology Collaboration Research Fund (No. 213021202) in Northwest A\&F University.

\section{REFERENCES}

Anifantakis, E. M. 2001. Utilization of goat milk. Pages 2-7 in Dairy News. Natl. Greek Dairy Comm. Int. Dairy Fed., Brussels, Belgium.

Beutin, L., D. Geier, H. Steinrück, S. Zimmermann, and F. Scheutz. 1993. Prevalence and some properties of verotoxin (Shiga-like toxin)-producing Escherichia coli in seven different species of healthy domestic animals. J. Clin. Microbiol. 31:2483-2488.

Blanco, M., J. Blanco, A. Mora, J. Rey, J. Alonso, M. Hermoso, J. Hermoso, M. Alonso, G. Dahbi, and E. González. 2003. Serotypes, virulence genes, and intimin types of Shiga toxin (verotoxin)-producing Escherichia coli isolates from healthy sheep in Spain. J. Clin. Microbiol. 41:1351-1356.

Claeys, W. L., C. Verraes, S. Cardoen, J. De Block, A. Huyghebaert, K. Raes, K. Dewettinck, and L. Herman. 2014. Consumption of raw or heated milk from different species: An evaluation of the nutritional and potential health benefits. Food Contr. 42:188-201.

CLSI (Clinical and Laboratory Standards Institute). 2013. Performance Standards for Antimicrobial Susceptibility Testing, Twenty-Second Informational Supplement, CLSI document M100-S23. Clin. Lab. Stand. Inst., Wayne, PA.

Cortés, P., V. Blanc, A. Mora, G. Dahbi, J. E. Blanco, M. Blanco, C. López, A. Andreu, F. Navarro, and M. P. Alonso. 2010. Isolation and characterization of potentially pathogenic antimicrobial-resistant Escherichia coli strains from chicken and pig farms in Spain. Appl. Environ. Microbiol. 76:2799-2805.

Craven, H. M., C. M. McAuley, L. L. Duffy, and N. Fegan. 2010. Distribution, prevalence and persistence of Cronobacter (Enterobacter sakazakii) in the nonprocessing and processing environments of five milk powder factories. J. Appl. Microbiol. 109:1044-1052.

De Buyser, M.-L., B. Dufour, M. Maire, and V. Lafarge. 2001. Implication of milk and milk products in food-borne diseases in France and in different industrialised countries. Int. J. Food Microbiol. $67: 1-17$.

Duffy, L. L., D. O'Callaghan, C. M. McAuley, N. Fegan, and H. M. Craven. 2009. Virulence properties of Escherichia coli isolated from Australian dairy powder factory environments. Int. Dairy J. 19:178-179.

Gautom, R. K. 1997. Rapid pulsed-field gel electrophoresis protocol for typing of Escherichia coli O157:H7 and other gram-negative organisms in 1 day. J. Clin. Microbiol. 35:2977-2980.

Ho, P.-L., K. Chow, E. L. Lai, W.-U. Lo, M. Yeung, J. Chan, P. Chan, and K. Yuen. 2011. Extensive dissemination of CTX-M-producing Escherichia coli with multidrug resistance to 'critically important' antibiotics among food animals in Hong Kong, 2008-10. J. Antimicrob. Chemother. 66:765-768.

Hornes, E., Y. Wasteson, and O. Olsvik. 1991. Detection of Escherichia coli heat-stable enterotoxin genes in pig stool specimens by an immobilized, colorimetric, nested polymerase chain reaction. J. Clin. Microbiol. 29:2375-2379.

IDF (International Dairy Federation). 1991. IDF Recommendations for the Hygienic Manufacture of Spray Dried Milk Powders. IDF Bulletin 267. Int. Dairy Fed., Brussels, Belgium.

Jacob, M., D. Foster, A. Rogers, C. Balcomb, X. Shi, and T. Nagaraja. 2013. Evidence of non-O157 Shiga toxin producing Escherichia coli in the feces of meat goats at a US slaughter plant. J. Food Prot. $76: 1626-1629$.

Koo, H. J., and G. J. Woo. 2011. Distribution and transferability of tetracycline resistance determinants in Escherichia coli isolated from meat and meat products. Int. J. Food Microbiol. 145:407413.

Lynch, M., L. O'Connor, E. Fox, K. Jordan, and M. Murphy. 2012. Verocytotoxigenic Escherichia coli O157, O111, O26, O103, O145 in Irish dairy cattle and raw milk: Prevalence and epidemiology of emergent stains. Zoonoses Public Health 59:264-271.

Martin, A., and L. Beutin. 2011. Characteristics of Shiga toxin-producing Escherichia coli from meat and milk products of different origins and association with food producing animals as main contamination sources. Int. J. Food Microbiol. 146:99-104. 
Mora, A., J. E. Blanco, M. Blanco, M. P. Alonso, G. Dhabi, A. Echeita, E. A. González, M. I. Bernárdez, and J. Blanco. 2005. Antimicrobial resistance of Shiga toxin (verotoxin)-producing Escherichia coli $\mathrm{O} 157: \mathrm{H} 7$ and non-O157 strains isolated from humans, cattle, sheep and food in Spain. Res. Microbiol. 156:793-806.

Oswald, E., H. Schmidt, S. Morabito, H. Karch, O. Marches, and A. Caprioli. 2000. Typing of intimin genes in human and animal enterohemorrhagic and enteropathogenic Escherichia coli: Characterization of a new intimin variant. Infect. Immun. 68:64-71.

Park, Y. W., M. Juárez, M. Ramos, and G. F. W. Haenlein. 2007. Physico-chemical characteristics of goat and sheep milk. Small Rumin. Res. 68:88-113.

Rey, J., J. E. Blanco, M. Blanco, A. Mora, G. Dahbi, J. M. Alonso, M. Hermoso, J. Hermoso, M. P. Alonso, and M. A. Usera. 2003. Serotypes, phage types and virulence genes of Shiga-producing Escherichia coli isolated from sheep in Spain. Vet. Microbiol. 94:47-56.

Rúgeles, L. C., J. Bai, A. J. Martínez, M. C. Vanegas, and O. G. Gómez-Duarte. 2010. Molecular characterization of diarrheagenic Escherichia coli strains from stools samples and food products in Colombia. Int. J. Food Microbiol. 138:282-286.

Scheutz, F., E. Møller Nielsen, J. Frimodt-Møller, N. Boisen, S. Morabito, R. Tozzoli, J. Nataro, and A. Caprioli. 2011. Characteristics of the enteroaggregative Shiga toxin/verotoxin-producing Escherichia coli O104:H4 strain causing the outbreak of haemolytic uraemic syndrome in Germany, May to June 2011. Euro Surveill. 16:19889.
Sethabutr, O., M. Venkatesan, G. S. Murphy, B. Eampokalap, C. W. Hoge, and P. Echeverria. 1993. Detection of Shigellae and enteroinvasive Escherichia coli by amplification of the invasion plasmid antigen $\mathrm{H}$ DNA sequence in patients with dysentery. J. Infect. Dis. 167:458-461.

Tamanai-Shacoori, Z., A. Jolivet-Gougeon, M. Pommepuy, M. Cormier, and R. Colwell. 1994. Detection of enterotoxigenic Escherichia coli in water by polymerase chain reaction amplification and hybridization. Can. J. Microbiol. 40:243-249.

Vieira, A. R., P. Collignon, F. M. Aarestrup, S. A. McEwen, R. S. Hendriksen, T. Hald, and H. C. Wegener. 2011. Association between antimicrobial resistance in Escherichia coli isolates from food animals and blood stream isolates from humans in Europe: An ecological study. Foodborne Pathog. Dis. 8:1295-1301.

Xu, Z.-Q., M. T. Flavin, and J. Flavin. 2014. Combating multidrugresistant Gram-negative bacterial infections. Expert Opin. Investig. Drugs 23:163-182

Yamasaki, S., Z. Lin, H. Shirai, A. Terai, Y. Oku, H. Ito, M. Ohmura, T. Karasawa, T. Tsukamoto, and H. Kurazono. 1996. Typing of verotoxins by DNA colony hybridization with poly- and oligonucleotide probes, a bead-enzyme-linked immunosorbent assay, and polymerase chain reaction. Microbiol. Immunol. 40:345-352.

Yang, H., S. Chen, D. G. White, S. Zhao, P. McDermott, R. Walker, and J. Meng. 2004. Characterization of multiple-antimicrobialresistant Escherichia coli isolates from diseased chickens and swine in China. J. Clin. Microbiol. 42:3483-3489. 